\title{
Distributed Ledger Technologies for Inclusive Postal Financial Services: Blockchain and More
}

\author{
Aditya Chidepatil \\ office@rigv.fi | Radical Innovations Group, Finland \\ Krishnaswamy Sankaran \\ krish@sankaran.org | Radical Innovations Group, Finland \\ Letter from Industry
}

\begin{abstract}
Distributed ledger technologies are emerging as important tools that can positively impact almost all major industries and activities in our society. They are increasingly used in various supply (value) chain applications including financial, governance, regulations, health, logistics, and other industrial sectors. In this letter, we are presenting various ongoing work related to different distributed ledger technologies and their applications in postal sector. In particular, we will highlight some of the innovations in the inclusive financial services for the underbanked and unbanked populations using distributed ledger technologies.
\end{abstract}

Keywords. Distributed Ledger Technology; DLT; Blockchain; Inclusive Financial Services; Postal Logistics; Supply Chain; Value Chain; Unbanked; Underbanked; Financial Services Innovation.

Cite paper as: Chidepatil, A., Sankaran, K., (2020). Distributed Ledger Technologies for Inclusive Postal Financial Services: Blockchain and More - Letter from Industry, Journal of Innovation Management, www.openjim.org, 8(3), 20-27. 


\section{Introduction}

Roy Amara claimed that "we tend to overestimate the effect of a technology in the short run and underestimate the effect in the long run"(Ratcliffe, 2016). History has many example and it will not be an exaggeration to relate this adage to the role and impact of different distributed ledger technologies (DLTs) on various activities of our society. Presently, DLTs are increasingly used in various supply (value) chain applications in financial, governance, regulations, health, logistics, and other industrial sectors. Advanced communication and information technologies are becoming integral part of postal products and services as a response to new customer expectations and developing competitive offerings (Crew \& Kleindorfer, 2012). Recent developments in DLTs offer many features suitable for postal services in particular to supply (value) chain and logistics, and inclusive financial services (Clotteau, Avsec, \& Grin, 2016; Perlman, 2017).

DLTs are new type of secured database or ledger for keeping track of ownership of physical, financial, or electronic asset without a centralized controller for validating and confirming the asset-related data (Perlman, 2017). This data, however, is shared, validated, and approved by a group of actors following certain complex procedures or protocols. DLTs have the power to simplify operations, provide transparency, guarantee credibility, and encourage decentralization in businesses, governments, and international organizations. The complex protocols, procedures, and implementations of DLT are fundamental to its core principles - transparency, immutability, and credibility of the information. They are targeted to foster multi-stakeholder interactions, communication, and sharing of information. Many of the development and adoption of DLTs are still in their nascent stage. Not all application domains are appropriate use-cases for employing DLT. One has to carefully investigate the techno-economic, social, and regulatory feasibility of various DLTs, where they add value, and identify the right DLT technology for an application, if at all, one finds benefit in employing them. Several DLT implementations are currently studied in the Radical Innovations Group, Finland for their operational efficacy, implementation flexibility, data security and integrity, among other things. We will briefly showcase our overall efforts and progress in this important area.

\section{Blockchain and more: the jungle of DLTs}

Several logistics and supply chain industries are exploring the potential of DLTs to improve and optimize their operations (Chidepatil et al., 2020; Sankaran, 2019). Particularly, postal services are aiming to facilitate transactions between various designated operators (DOs), issuance of certificates of origin for postal items, collection-point identity management, and entire supply chain of postal goods including logistics. Furthermore, postal services are increasingly involved in connecting underbanked and unbanked sections of our society to various inclusive financial services (Anson, Berthaud, Klapper, \& Singer, 2013).

There are 5 main types of relevant DLTs, namely, Blockchain, Hashgraph, DAG, Holochain, and Radix. Of these, Blockchain is one of the most important technologies that has gained popularity - thanks to various use-cases built using this technology. There are also some very interesting, simplified, flexible and more robust options possible while going with the other DLTs. A high- 
level comparison of different DLTs emphasizing their capabilities and differences is shown in Fig. 1 (Schueffel, 2017; Pervez, Muneeb, Irfan, \& Haq, 2018; Ioini \& Pahl, 2018).

\begin{tabular}{|c|c|c|c|c|c|}
\hline Aspects & Blockchain & Hashgraph & DAG & Holochain & Radix \\
\hline $\begin{array}{l}\text { Data } \\
\text { structure }\end{array}$ & $\begin{array}{l}\text { In the form of } \\
\text { blocks decided by } \\
\text { the order of } \\
\text { transactions } \\
\text { validated by } \\
\text { miners }\end{array}$ & $\begin{array}{l}\text { Using Directed } \\
\text { Acyclic Graph }\end{array}$ & $\begin{array}{l}\text { Using Directed } \\
\text { Acyclic Graph }\end{array}$ & $\begin{array}{l}\text { Distribution of } \\
\text { data among } \\
\text { various nodes }\end{array}$ & $\begin{array}{l}\text { In the form of subset } \\
\text { of the ledger called } \\
\text { shards that is } \\
\text { uniquely identified }\end{array}$ \\
\hline $\begin{array}{l}\text { Consensus } \\
\text { mechanism }\end{array}$ & $\begin{array}{l}\text { Different mining } \\
\text { protocols }\end{array}$ & $\begin{array}{l}\text { Based on } \\
\text { virtual voting } \\
\text { and } \\
\text { gossip about } \\
\text { gossip }\end{array}$ & $\begin{array}{l}\text { Previous } \\
\text { transaction } \\
\text { validates the } \\
\text { succeeding one }\end{array}$ & Not required & $\begin{array}{l}\text { By registering, } \\
\text { coordinating, and } \\
\text { preserving the total } \\
\text { order of event }\end{array}$ \\
\hline $\begin{array}{l}\text { Transaction } \\
\text { validation }\end{array}$ & $\begin{array}{l}\text { Miners can } \\
\text { postpone or } \\
\text { cancel the } \\
\text { complete } \\
\text { transaction }\end{array}$ & $\begin{array}{l}\text { Virtual voting is } \\
\text { used to validate } \\
\text { transactions }\end{array}$ & $\begin{array}{l}\text { Present } \\
\text { transaction will } \\
\text { be approved } \\
\text { if and only if } \\
\text { two previous } \\
\text { transactions are } \\
\text { validated }\end{array}$ & $\begin{array}{l}\text { Miners are not } \\
\text { needed for } \\
\text { validation as } \\
\text { each node } \\
\text { processes its } \\
\text { own ledger }\end{array}$ & $\begin{array}{l}\text { Atom is validated by } \\
\text { a subset of nodes, } \\
\text { after which temporal } \\
\text { proof i.e. crypto- } \\
\text { graphically secure } \\
\text { record of sequentially } \\
\text { ordered events is } \\
\text { constructed }\end{array}$ \\
\hline $\begin{array}{l}\text { Transactions } \\
\text { per second } \\
\text { (TPS) }\end{array}$ & $\begin{array}{l}\text { Scalability and } \\
\text { TPS are highly } \\
\text { limited }\end{array}$ & $\begin{array}{l}\text { High because } \\
\text { of its unique } \\
\text { consensus } \\
\text { mechanism that } \\
\text { reduces } \\
\text { computational } \\
\text { load }\end{array}$ & $\begin{array}{l}\text { High TPS and } \\
\text { scalability are } \\
\text { ensured through } \\
\text { unique directed } \\
\text { acyclic graph } \\
\text { data structure }\end{array}$ & $\begin{array}{l}\text { Limitless } \\
\text { scalability and } \\
\text { TPS is achieved } \\
\text { through } \\
\text { independent } \\
\text { ledger system } \\
\text { for each node }\end{array}$ & $\begin{array}{l}\text { High scalability and } \\
\text { TPS are ensured by } \\
\text { logical time ordering } \\
\text { in combination with } \\
\text { sharded DAG data } \\
\text { structure }\end{array}$ \\
\hline
\end{tabular}

Fig. 1. Comparison of 5 major DLT implementations

\section{Challenges of inclusive financial services: unbanked and under- banked population}

There are many challenges in inclusive finance which hinder expanding financial services to unbanked and underbanked populations in our society. The first and foremost reason is that underprivileged section of the society do not have any personal identification documents (IDs) (Dev, 2006). This is a major hurdle faced by many poor and marginalized communities, in particular, in developing and underdeveloped countries.

In most countries, some sort of ID is mandatory for opening a bank account. These days many social benefits are also linked to national IDs. Popular examples of these national IDs include European social security card and Indian Aadhaar card. The process for obtaining these IDs requires other forms of primary identification proofs. In other words, these national IDs are not given to people without other primary or secondary identification proofs such as birth certificate, school-leaving certificate, population registry document from the local village 
or municipality (domicile certificate), etc. But not everyone have access to these primary or secondary documents, especially the rural poor. Thus, we end up in a never-ending cycle which makes it more complicated for the unbanked and underbanked to gain access to basic financial services. This is where different digital technologies can be successfully employed to develop alternative pathways for providing personal ID (Clotteau et al., 2016).

Two connected issues to the above challenge are gender and wealth inequalities. Findex reported in 2014 that approximately 1.1 out of 2 billion unbanked individuals around the world were women. In 2017, 0.95 out of 1.7 billion unbanked individuals were women (Demirguc-Kunt, Klapper, Singer, Ansar, \& Hess, 2018). Furthermore, many field studies reveal that the poor or lack of financial awareness prevents many from disadvantaged communities from utilizing financial appropriate products and services suitable for their needs (Dev, 2006; Sarma \& Pais, 2011; Arun \& Kamath, 2015). By building basic financial awareness in these demographics, we can surely improve their uptake of new bank accounts and hence, increase their saving potential and credit rating. Furthermore, encouraging rural poor and women to gain skills in basic money management topics, we can help them in making better-informed financial decisions.

Studies conducted by the World Bank and International Financial Corporation (IFC) have highlighted the vicious circle in which many rural women are trapped. They are denied credits by financial institutions largely due to a lack of collateral or poor credit history at the first place (Bruhn et al., 2017). This is akin to denying access to education because you are uneducated. This logic of decision-making by the financial institutions remained largely unchallenged.

In order to expand financial inclusion among the rural poor, particularly women, stakeholders must create new pathways that can avoid some of the aforementioned bottlenecks. Women, in general, have lower chance of securing credit from banks even though they represent most part of the self-employed category in many developing countries. They often end up paying higher interest rates compared to men, even if they manage to secure formal credit from banks. These gender-based bias make it very challenging to women to overcome these structural financial barriers in their effort to get out of the Sisyphean task. New pathways to financial inclusion should provide target groups with alternative (digital) IDs that can be used to open savings account and to build up credit history from an early age.

However, opening a bank account is just the first step, and not the ultimate goal. Many individuals in developing countries still resort to cash for their personal and business transactions. In 2014, 355 million adults in developing countries with bank accounts still resorted to remitting money by cash or over the counter (Demirguc-Kunt, Klapper, Singer, \& Oudheusden, 2015). These individuals still do not see their bank account as a useful mode for transactions. We can only change this trend by tying their bank accounts to various social and economic benefits. A recent example in India is Pradhan Mantri Jan-Dhan Yojana (PMJDY) program. The Indian government directly handed out various social benefits and subsidies to the recipients' basic bank accounts, and hence, making them acquainted to various basic banking services (GoI, 2014). These are the first, yet very important steps in the long process of engaging rural poor and women in the financial inclusion journey. 


\section{Innovative postal services for inclusive finance}

The postal service currently offers some basic financial services, including international electronic money transfers. These services could be offered through a digital format in a cheaper and more efficient manner for both the customers and the postal stakeholders. Postal services are increasingly using modern DLT tools to deliver inclusive financial services (Perlman, 2017). There are ongoing work to develop use-cases involving cryptocurrencies for postal transactions (Khan, 2019).

There are several ongoing discussions and debates on regulating cryptocurrencies in various countries. In the proposed state-of-the-art DLT-based solutions for various supply (value) chain processes, the main emphases are on the data structure, consensus and validation mechanisms of the DLT without the cryptocurrency feature. Here, we would like to highlight two important aspects of the presented DLT-based solutions. First, we are able to serve the unbanked and underbanked populations using their biometric information or other alternative modes such as digital IDs, mobile wallets, and ID-less prepaid cards. Second, the proposed solutions can be easily integrated with ongoing efforts of other UN bodies, non-governmental, and international organizations. For example, World Bank Group's (WBG) work on identification for development (ID4D) is an interesting case in point for which these proposed DLT-based solutions can be easily adapted (Group, 2018, 2019).

The main strengths of these DLT-based solutions are due to their collective, transparent, and credible processes mapping the entire postal supply (value) chain. An overview of our state-ofthe-art inclusive postal financial services using appropriate DLTs for providing various products and services to the underbanked and unbanked population is illustrated in Fig. 2.

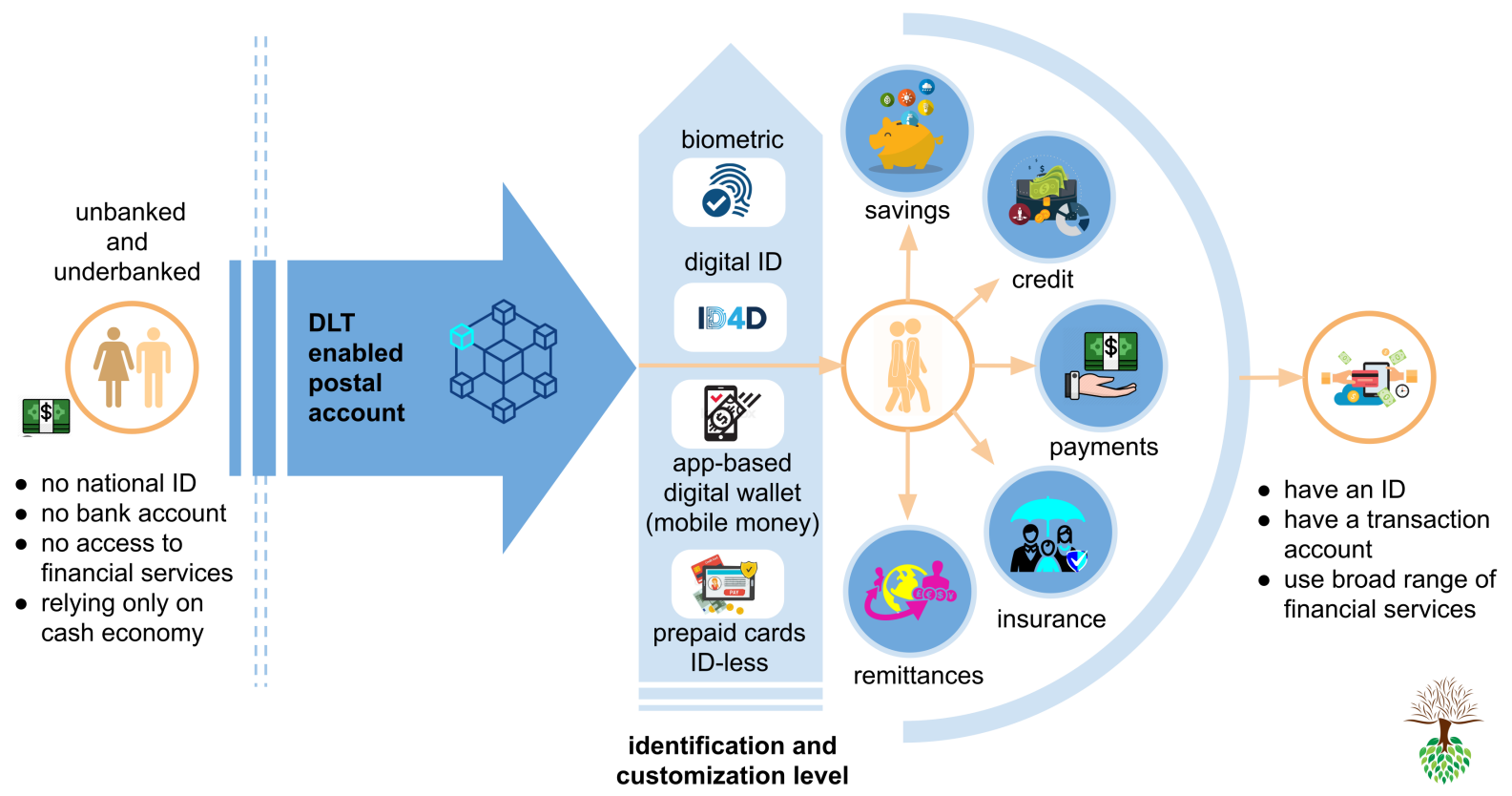

Fig. 2. DLT-enabled state-of-the-art inclusive postal financial services 
Economic independence and inclusive participation are key to progress in any society. In that sense, one can tap on the democratic nature of DLTs. Particularly, the advanced inclusive finance solutions will open new opportunities for the unbanked and underbanked population to save money, get loans and credits, apply for insurances, receive and remit payments using alternative or new DLT-enabled transaction modes.

In addition to Blockchain, we are also presently evaluating and experimenting other DLTs such as Hashgraph, DAG, Holochain, and Radix. We are mainly interested in simplified yet robust implementation of DLT protocols that are agile and flexible to changes in the customer specifications. In addition to these requirements, one can aim for high level of data security, integrity, and validation while employing these DLT-based solutions.

\section{Conclusion}

We have tapped on the democratic nature of DLTs providing transparent and credible inclusive financial services mapping the entire supply (value) chain. We have discussed how distributed ledger technologies are opening up new opportunities for providing inclusive financial services to underprivileged sections of our society, who are generally excluded from using traditional banking services. By systematically understanding and addressing challenges such as lack of proper identification documents, gender and wealth inequalities, and poor financial literacy, we are able to provide alternative DLT-based solutions to the unbanked and underbanked population. Several DLT implementations are currently studied in the Radical Innovations Group, Finland for their operational efficacy, implementation flexibility, data security and integrity, among other things. We have summarized the main DLT implementations highlighting their strengths and important differences. Going forward these DLT-based solutions will increasingly transform various traditional industries and operations in our society opening new opportunities for innovation.

\section{References}

Anson, J., Berthaud, A., Klapper, L., \& Singer, D. (2013). Financial inclusion and the role of the post office. World Bank Group. doi: 10.1596/1813-9450 -6630

Arun, T., \& Kamath, R. (2015). Financial inclusion: Policies and practices. IIMB Management Review, 27(4), 267-287. doi: 10.1016/j.iimb.2015.09 .004

Bruhn, M., Hommes, M., Khanna, M., Singh, S., Sorokina, A., \& Wimpey, J. S. (2017). MSME FINANCE GAP: Assessment of the Shortfalls and Oppor- tunities in Financing Micro, Small and Medium Enterprises in Emerging Markets (Vol. 1; Tech. Rep.). International Finance Corporation, World Bank Group.

Chidepatil, A., Bindra, P., Kulkarni, D., Qazi, M., Kshirsagar, M., \& Sankaran, K. (2020). From Trash to Cash: How Blockchain and Multi-Sensor- driven AI Can Transform Circular Economy of Plastic Waste? Administrative Sciences, 10(2), 23. Retrieved from: https://doi.org/10.3390/ admsci10020023 
Clotteau, N., Avsec, D., \& Grin, Y. (2016). The Role of Postal Networks in Digital Financial Services (Tech. Rep.). International Telecommunications Union.

Crew, M. A., \& Kleindorfer, P. R. (2012). Managing change in the postal and delivery industries (Vol. 25). Springer Science \& Business Media.

Demirguc-Kunt, A., Klapper, L., Singer, D., Ansar, S., \& Hess, J. (2018).

The Global Findex Database 2017: Measuring Financial Inclusion and the Fintech Revolution. The World Bank. (ISBN (electronic): 978-1-4648- 1268-2) doi: 10.1596/978-1-4648-1259-0

Demirguc-Kunt, A., Klapper, L., Singer, D., \& Oudheusden, P. V. (2015). The Global Findex Database 2014: Measuring Financial Inclusion around the World (Tech. Rep. No. WPS7255).

Dev, S. M. (2006). Financial Inclusion: Issues and Challenges. Economic and Political Weekly, 41(41), 4310-4313. Retrieved from: https://www.jstor .org/stable/4418799

GoI. (2014). Pradhan Mantri Jan-Dhan Yojna: A National Mission on Finan- cial Inclusion. Ministry of Finance, Government of India. Retrieved from: https://pmjdy.gov.in/

Group, W. B. (2018). Global ID Coverage, Barriers, and Use by the Numbers: Insights from the ID4D-Findex Survey (Vol. 1; Tech. Rep.). Retrieved from: https://id4d.worldbank.org/

Group, W. B. (2019). Identification for Development (ID4D) Practitioner's Guide (Vol. 1; Tech. Rep.). Retrieved from https://id4d.worldbank .org/

Ioini, N. E., \& Pahl, C. (2018). A Review of Distributed Ledger Technologies. , 277-288. doi: 10.1007/978-3-030-02671-4 16

Khan, S. (2019). Potential use cases of cryptocurrencies by Posts: A White Pa- per on Postal Financial Inclusion (Tech. Rep.). Universal Postal Union.

Perlman, L. (2017). Distributed ledger technologies and financial inclusion (Tech. Rep.). International Telecommunications Union.

Pervez, H., Muneeb, M., Irfan, M. U., \& Haq, I. U. (2018). A comparative analysis of DAG-based blockchain architectures. , 27-34. doi: 10.1109/ ICOSST.2018.8632193

Ratcliffe, S. (2016). Oxford Essential Quotations. Oxford University Press.

doi: 10.1093/acref/9780191826719.013.q-oro-ed4-00018679

Sankaran, K. (2019). Carbon Emission and Plastic Pollution: How Circular Economy, Blockchain, and Artificial Intelligence Support Energy Transition? Journal of Innovation Management , 7 (4). Retrieved from https://doi.org/10.24840/2183-0606_007.004_0002

Sarma, M., \& Pais, J. (2011). Financial inclusion and development. Journal of International Development, 23(5), 613-628. doi: 10.1002/jid.1698

Schueffel, P. (2017). Alternative Distributed Ledger Technologies Blockchain vs. Tangle vs. Hashgraph - A High-Level Overview and Comparison -. SSRN Electronic Journal, 1-8. doi: $10.2139 /$ ssrn. 3144241 


\section{Biographies}

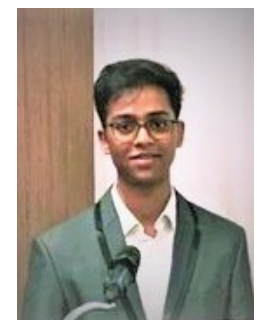

Aditya Chidepatil. A. Chidepatil is currently pursuing final year of bachelor degree in computer science and engineering in the Government College Engineering, Aurangabad, India. Along with his studies, he is directly working under the guidance of Dr. K. Sankaran in different industrial projects ongoing in Radical Innovations Group AB, Finland. He is also doing his bachelor thesis in the Radical Innovations Group. His interests are in circular materials and energy, modelling and simulations, and DLT applications in industry.

CRediT Statement: Investigation, Visualization.

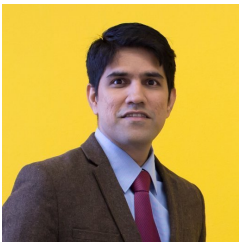

Krishnaswamy Sankaran. Dr. K. Sankaran is an established industrialist with several years of experience in energy, utilities, metals, mining, infrastructure, production, and recycling industries. He is presently the Chief Executive Officer of the Radical Innovations Group AB, Finland. He received doctorate in engineering sciences from the Swiss Federal Institute of Technology ETH Zurich, Switzerland, masters from Karlsruhe Institute of Technology KIT, Germany, and a joint executive masters in organisational development and leadership from Wharton School, Columbia University, INSEAD, and London Business School. He is a recognized thought leader and keynote speaker in many international forums. He has several years of training in Advaita philosophy.

CRediT Statement: Conceptualization, Methodology, Validation, Formal Analysis, Resources, Data Curation, Writing - Original Draft, Writing - Review \& Editing, Supervision, Project Administration. 